\title{
EVALUATION OF MANUFACTURING TOLERANCE USING A STATISTICAL METHOD AND EXPERIMENTATION
}

\author{
Barkallah, M.; Louati, J. \& Haddar, M. \\ Mechanics Modelling and Production Research Unit (U2MP) \\ University of Sfax, Sfax Engineering School (E.N.I.S.), B.P 1173, 3038 Sfax, Tunisia \\ E-Mail: bark_maher@yahoo.fr
}

\begin{abstract}
This paper proposes a study of a milling process planning to determine the tolerancing for manufacturing using statistical tool. The deviation between the machined surface and the surface corresponding to the nominal one due to combined errors is expressed in terms of the small displacement torsor parameters. These parameters are considered as random variables, displacements are expresses as variances. Experimentation is realised on a set of manufactured parts which consists of measuring various defects on machine-tool. The experimental results and the simulation results are compared in this paper.

(Received in March 2011, accepted in August 2011. This paper was with the authors 1 month for 1 revision.)
\end{abstract}

Key Words: Manufacturing Tolerancing, Statistical Analysis, Simulation, Three-Dimensional Model, Process Planning

\section{INTRODUCTION}

Manufacturing tolerancing is intended to determine the intermediate geometrical and dimensional states of the part during its manufacturing process. These manufacturing dimensions also serve to satisfy not only the functional requirements given in the definition drawing, but also the manufacturing constraints.

This topic has drawn considerable attention, and many papers have been published on one, two and three-dimensional tolerancing. A very broad review of the tolerancing method is presented in Wang et al. [1]. In industry, the most common approaches are simply unidirectional and often based on the $\Delta l$ method [2-4]. Such approaches are not able to handle small angular deviations from one machining phase to the next. The purpose of threedimensional approaches is to manage the small angular deviations occurring between the various machining phases.

Preliminary work motivating the development of the 3D tolerance propagation techniques is regarded as the spatial dimensional chain technique [5], the propagation of position errors is taken into account in terms of a kinematic chain, where the individual error is represented as matrices with three-dimensional and three angular position errors. For pairs of functional elements in a kinematic chain model is associated with a set of six virtual joints, three for small translations, and three for small rotations [6]. Three-dimensional tolerance propagation models based on the concept of a small displacement torsor (SDT) are used to simulate threedimensional fixturing and machining errors and their impacts on the geometry of the finished part. The SDT is a mathematical object that represents the displacement of a rigid body using three rotations and three translations. This approach models the influence of a process plan on functional tolerances as a chain of torsors [7, 8]. The SDT-based and three-dimensional tolerance propagation overcomes such limitations. Based on the SDT method, a detailed model of mechanical parts, part-holders, and machining operations was developed $[9,10]$ and extended to tolerance synthesis [11, 12]. Vectorial tolerancing can be applied to geometrical 
tolerance analysis, see [13] for example. A simulation-based tolerance stack-up analysis was proposed [14], the Monte Carlo method is used to perform the simulation. The different possible errors are studied and it is assumed that Part/Fixture contact is perfect. Alternatively, a graphical representation of part features, process plans, and functional requirements defined with an ISO standard can be employed to analyze three-dimensional tolerance specifications and to generate manufacturing specifications compatible with ISO standards [15]. Based on the TTRS approach [16], a set of algorithm allowing the development of manufacturing specification was proposed $[17,18]$.

The different reviewed papers do not discuss the estimated sources of error whether from a theoretical model and/or experimental measurements. To perform realistic simulations, it is now necessary to dispose of experimental data values. In this paper a 3-D geometrical manufacturing simulation model is presented. It describes the geometrical errors of part surfaces with a statistical approach. The aim of realistic simulation is to anticipate the behaviour of the manufacturing process with respect to its capacity to obtain parts in conformity with drawing office specifications. Conformity of parts being manufactured is verified by means of tolerancing specifications for manufacturing [19-22]. Passing from one to another of these types of tolerancing specification entails a specification transfer operation which involves seeking the tolerancing specification for manufacturing and a resolution method. Simulation is validated by comparing simulated tolerancing values with those obtained from an experimental case study.

\section{THE PROBLEM UNDER STUDY}

\subsection{Functional definition drawing}

The part to be studied is written in accordance with ISO standards by defining the position and size of the tolerance zones within a reference system as presented in Fig. 1. In this paper, a single functional requirement $C 3$ is studied. The reference $B$ is a plane tangent to the real part surface. The nominal plane is defined by a theoretical dimension of $5 \mathrm{~mm}$ from reference $B$. The tolerance zone $0.4 \mathrm{~mm}$ is the space between two planes centred on the nominal plane. All points on the real specified surface must lie within the tolerance zone.
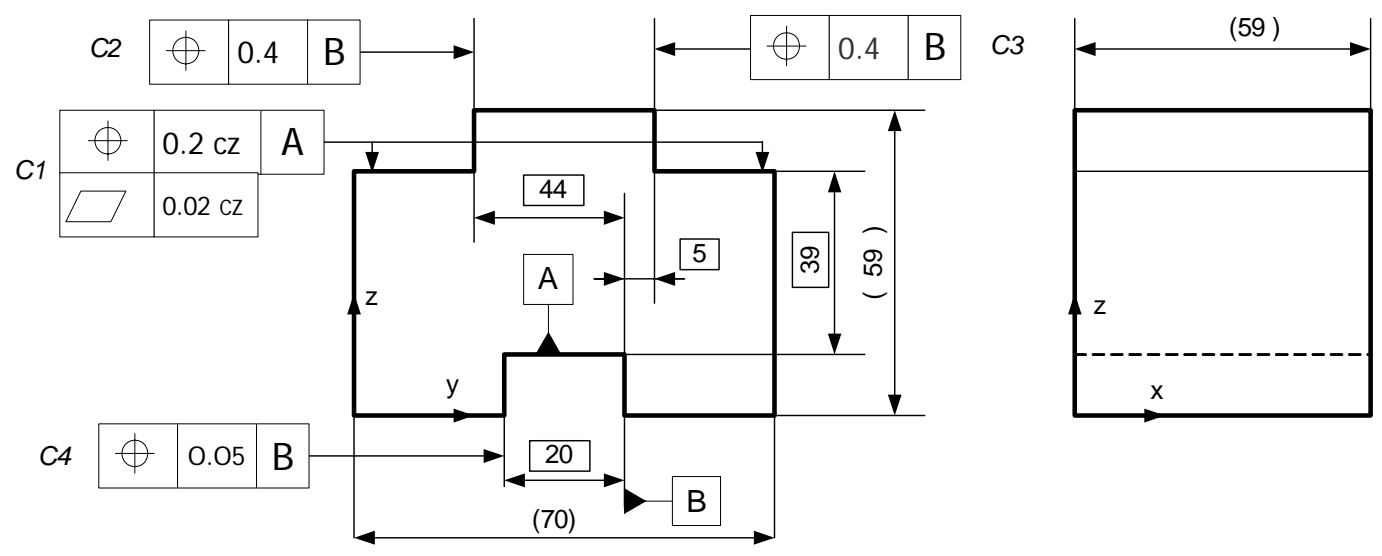

Figure 1: Dimensioning and tolerancing specifications on a design draft.

\subsection{Tolerancing specification for manufacturing}

The manufacturing process plan presented in Fig. 2 is performed on a numerical control (NC) machine tool. The machined surfaces have been denoted " $S_{i}$ " and the raw surfaces " $B_{i}$ ". 
The functional requirement $C 3$ is the localisation of surface $S_{1}$ in relation to surface $S_{6}(B)$. These surfaces $\left(S_{1}\right.$ and $\left.S_{6}\right)$ are machined respectively in phases $10\left(S_{1}\right)$, and $20\left(S_{6}\right)$. The surfaces are not generated in the same phase. The functional tolerance is obtained with two phases.

\begin{tabular}{|l|l|l|l|}
\hline \multicolumn{1}{|c|}{ Phase number } & Active surface \\
\hline Phase 00: & & \\
Receipt of raw \\
$70 \times 59 \times 59$
\end{tabular}

Figure 2: Manufacturing process plan.

The strategy for searching for specifications to be included in the phase contract is supported by the structure of specifications for design and process planning.

In this paper, we suppose that the qualitative generation of manufacturing specifications is already dealt with the rational method of $3 \mathrm{D}$ manufacturing tolerancing $[17,18]$. The reduction of reference surfaces in a geometric specification of manufacturing is done in an automated manner by applying different equations, originally developed by [23]. The manufacturing specifications (generated by a transfer) obtained for the studied requirement C3 are represented on manufacturing drawings presented in Fig. 3.

We propose through a statistical method based on small displacement torsor parameters, to treat the second point which is the determination of manufacturing tolerances in a quantitative aspect.

This work will enable:

- to validate a planning process taking in to account the different dispersions of manufacturing process (fixturing, machining, ...),

- to determine, for every manufacturing specification, the adopted tolerances. 


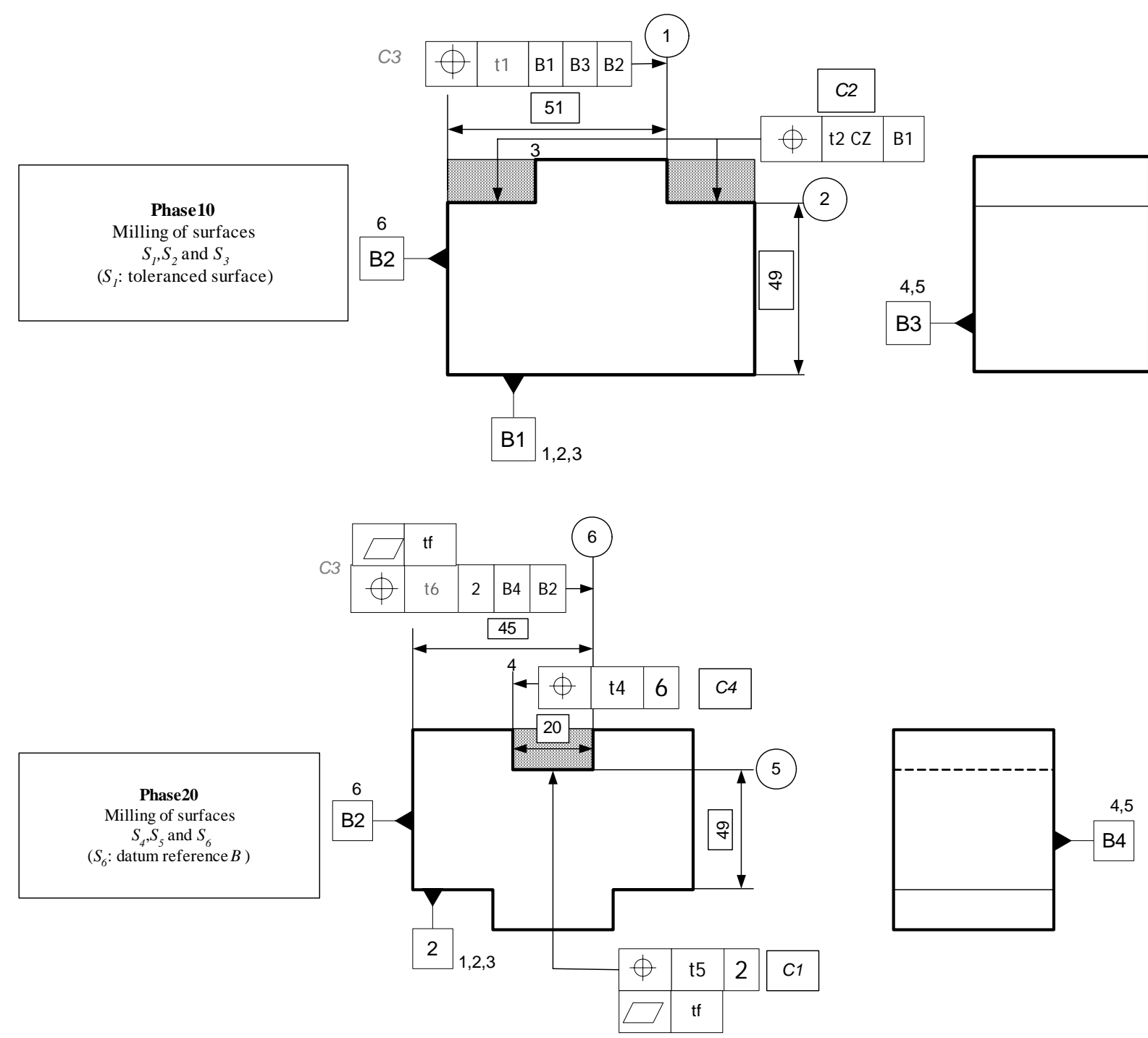

Figure 3: Manufacturing drawings.

\section{THREE-DIMENSIONAL TOLERANCING MODEL}

The proposed work consists on developing a statistical method for the simulation of 3D manufacturing tolerancing which allows the evaluation of the manufacturing tolerances zone. This method based on the components of the small displacements torsors which are considered as random variables. The small displacement torsors (SDT) associated with every surface of the chain is transported on the target surface and act as generators of disturbances. They are applied in several points defining the nominal surface and so generate points of the resultant tolerance zone.

\subsection{Statistical aspect of deviation torsor}

The small displacement torsor (SDT) is used to define the geometrical defects of machined surfaces. The SDT concept is based upon the movements of a rigid body [6]. It is defined by two vectors representing the values of three small rotations $\vec{\Omega}(\alpha, \beta, \gamma)$ and three small translations $\vec{D}_{O}(u, v, w)$ of a point $O$ of the body. In this case, the displacement of any point $M_{i}$ of the body is obtained by: 


$$
\vec{D}_{M_{i}}=\vec{D}_{O}+\vec{\Omega} \wedge \overrightarrow{O M_{i}}
$$

The small displacement of the considered surface is characterized by a torsor defined in the coordinate frame, $R$ as:

$$
[T]_{(O, R)}=\left[\begin{array}{l}
\vec{\Omega} \\
\vec{D}_{O}
\end{array}\right]_{(O, R)}=[\alpha \beta \gamma u v w]_{(O, R)}^{T}
$$

In this study, the six components of the SDT are considered as random variables. It should be noted that a torsor is defined by a point and a basis. The change of a point and the base of torsor is achieved by a base point and a $6 \times 6$ transformation matrix.

For any change of torsor reference of a wrench, the following matrix relation is then used:

$$
\left[\begin{array}{l}
\vec{\Omega}_{\left(\vec{x}_{2}, \vec{y}_{2}, \vec{z}_{2}\right)} \\
\vec{D}_{O_{2\left(\vec{x}_{2}, \vec{y}_{2}, \vec{x}_{2}\right)}}
\end{array}\right]=\left[\begin{array}{cc}
{\left[P_{12}^{-1}\right]} & {[0]} \\
{\left[-P_{12}^{-1} \cdot \tilde{\kappa}_{1}^{2}\right]} & {\left[P_{12}^{-1}\right]}
\end{array}\right] \cdot\left[\begin{array}{l}
\vec{\Omega}_{\left(\vec{x}_{1}, \vec{y}_{1}, \vec{z}_{1}\right)} \\
\vec{D}_{O_{1\left(\vec{x}_{1}, \vec{y}_{1}, \vec{x}_{1}\right)}}
\end{array}\right]
$$

where $\tilde{\kappa}_{1}^{2}$ represents the matrix of pre-vector product of the vector $\overrightarrow{O_{1} O_{2}}$.

Components of the deviation torsor expressed at the base point $O_{1}\left(\vec{x}_{1}, \vec{y}_{1}, \vec{z}_{1}\right)$ were assumed to be independent. The covariance matrix of the random vector defining this torsor is diagonal. In general, the linear change of variable $\boldsymbol{Y}=K \boldsymbol{X}$, where $\boldsymbol{X}$ and $\boldsymbol{Y}$ are random vectors and $K$ is a constant matrix, the covariance matrix of the random vector $Y$ is obtained by:

$$
\operatorname{cov}(\boldsymbol{Y})=K^{T \cdot} \operatorname{cov}(\boldsymbol{X}) \cdot K
$$

The covariance matrix associated with the deviation torsor of the surface $S$ expressed at point $\boldsymbol{O}_{2}$ in the base $\left(\vec{x}_{2}, \vec{y}_{2}, \vec{z}_{2}\right)$ is therefore deduced from relationships (3) and (4). It is then necessary to work in a unique reference, which will be called part reference. Eqs. (3) and (4) allow deducing the statistical characteristics of the resulting deviation torsor.

The resulting deviation is the sum of random deviations torsors intervening in the equation of the chain. For each deviation torsor involved in this relationship, there is a passage matrix $P_{k}$ which allows changing the local coordinate system (centre of the surface studied) to the global coordinate system (reference part). The statistical characteristics of the resulting deviation $\left(T_{r}\right)$ are deducted from the following equation:

$$
\operatorname{cov}\left(T_{r}\right)=P_{1}^{T} \operatorname{cov}\left(T_{1}\right) P_{1}+P_{2}^{T} \operatorname{cov}\left(T_{2}\right) P_{2}
$$

The variance in the displacement of a point $M_{i}$ in the normal direction of the surface is obtained by projecting following a unitary normal vector (shown as $\vec{n}_{S}$ in Fig. 4). The projection is expressed by the relation:

$$
V_{M_{i}, \overrightarrow{n_{S}}}=\sigma_{\overrightarrow{D_{M_{i}}} \cdot \vec{n}_{S}}^{2}=\left[\vec{n}_{S}\right]^{T} \overline{\bar{\Sigma}}\left[\vec{n}_{S}\right]
$$

\subsection{Study of a machining step}

The objective of this study is to determine the deviation between the real surface and the corresponding nominal surface, depending on the different influential defects in the manufacturing process. This deviation is defined by displacing point $M_{i}^{S}$ of real surface with respect to the corresponding point $M_{i}^{N}$ on the nominal part model as presented in Fig. 4. 


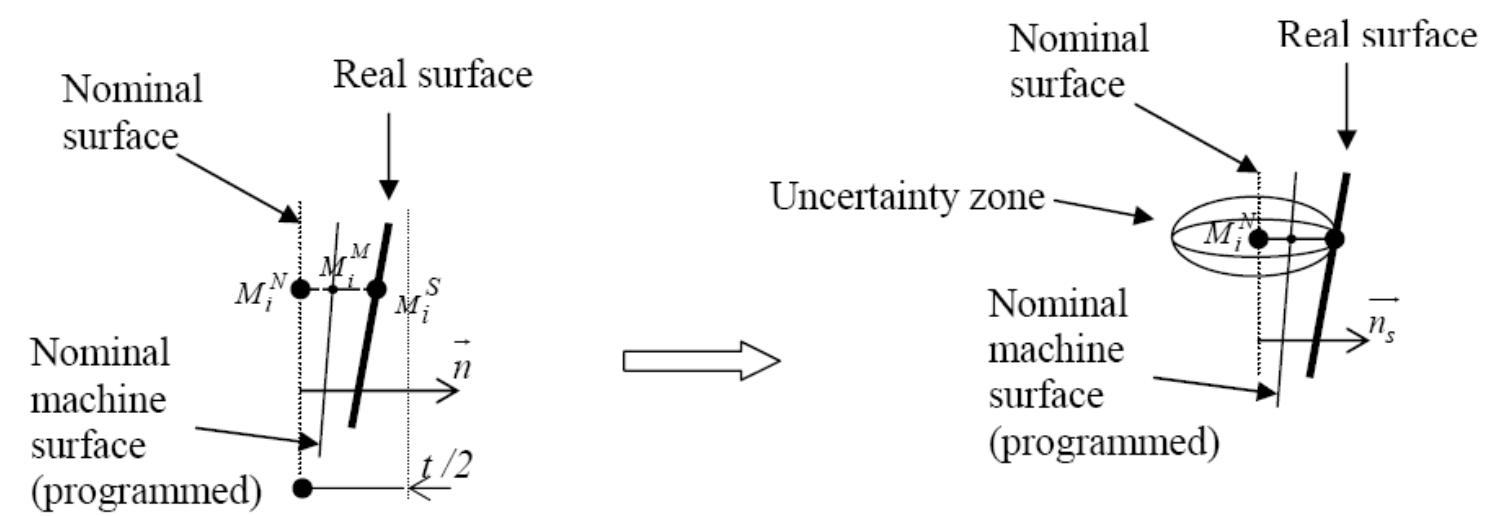

worst case

Statistical

Figure 4: Deviation between the toleranced surface and the nominal part.

The deviation between point $M_{i}^{S}$ and nominal surface $\overrightarrow{M_{i}^{N} M_{i}^{S}}$ is obtained by summing two deviations:

where:

$$
\overrightarrow{M_{i}^{N} M_{i}^{S}} \cdot \vec{n}=\overrightarrow{M_{i}^{N} M_{i}^{M}} \cdot \vec{n}+\overrightarrow{M_{i}^{M} M_{i}^{S}} \cdot \vec{n}
$$

- $\overrightarrow{M_{i}^{N} M_{i}^{M}} \cdot \vec{n}$ : Deviation between nominal part surface and nominal machine surface. This deviation is the displacement of point $M_{i}^{N}$, which can be calculated with the small displacement torsor.

- $\overrightarrow{M_{i}^{M} M_{i}^{S}} \cdot \vec{n}$ : Deviation of machined surface $S_{i}$ with respect to the nominal machine surface (programmed surface). This deviation can in theory be directly measured at each point $M_{i}$ using a Renishaw probe that assumes machine-tool defects are smallest as either tool defects or part deformations.

In our approach, we do not treat the case of a part, but the image of a series of parts. Present when manufacturing a surface, the following dispersions in the positioning system can by recovered when manufacturing a surface:

- Dispersions about the position of the toleranced element.

- Dispersions about the position of the referenced elements.

These dispersions depend on the manufacturing process such as machining and positioning of the workpiece.

Based on the hypothesis of small displacement around the nominal position, due to variation of positioning and dimensionally stable solids, it can be shown that the variance in the displacement of a point of a surface in a given direction can be calculated by:

$$
V_{M, \overline{n_{S}}}=\sigma_{\overline{D_{M_{i}}}}^{2} \cdot \vec{n}_{S}=\left[\vec{n}_{S}\right]^{T} \overline{\bar{\Sigma}} \underset{p o s, M i}{ }\left[\vec{n}_{S}\right]
$$

where:

- $\left[\vec{n}_{s}\left(a_{i}, b_{i}, c_{i}\right)\right]$ is the single column matrix of the unit vector coordinates defining the calculation direction,

- $\quad \overline{\bar{\Sigma}}_{\text {pos, } M_{i}}$ is the $3 \times 3$ matrix to calculate the variance at each point $M_{i}$ of the terminal surface. Its components depend on the coordinates of $M(x, y, z)$, the coordinates of the part-holder support points $A_{i}\left(X_{A i}, Y_{A i}, Z_{A i}\right)$, the normal at contact $\vec{n}_{\mathrm{Ai}}\left(n_{x i}, n_{y i}, n_{z i}\right)$ and the variation of the position at the points of contact $\delta_{i}$. 
To get the total local variance, adding the variance of machining defects obtained by direct measurement on the machine at each point $M_{i}$ using a Renishaw probe can be sufficient:

$$
\sigma_{\text {Total } / \overrightarrow{n_{S}}}^{2}=\left[\vec{n}_{S}\right]^{T} \overline{\bar{\Sigma}}_{\text {pos, Mi }}\left[\vec{n}_{S}\right]+\sigma_{\text {machining }}^{2}
$$

These results are true if the points of the parts are centred on the average position or are offset in relation to this position.

\section{NUMERICAL VALIDATION OF DEVELOPPED MODEL}

\subsection{Influence of dispersions in phase 10}

In phase 10 , the part studied is placed on the isostatic part-holder by a primary support $\left(A_{1}, A_{2}\right.$ and $\left.A_{3}\right)$ on the surface $B_{1}$, a secondary support $\left(A_{4}\right.$ and $\left.A_{5}\right)$ on the surface $B_{2}$ and tertiary support $\left(A_{6}\right)$ on the surface $B_{3}$.

Fig. 5 illustrates the position of $A_{1}$ to $A_{6}$ and $M_{1}$ to $M_{4}$ in phase 10.
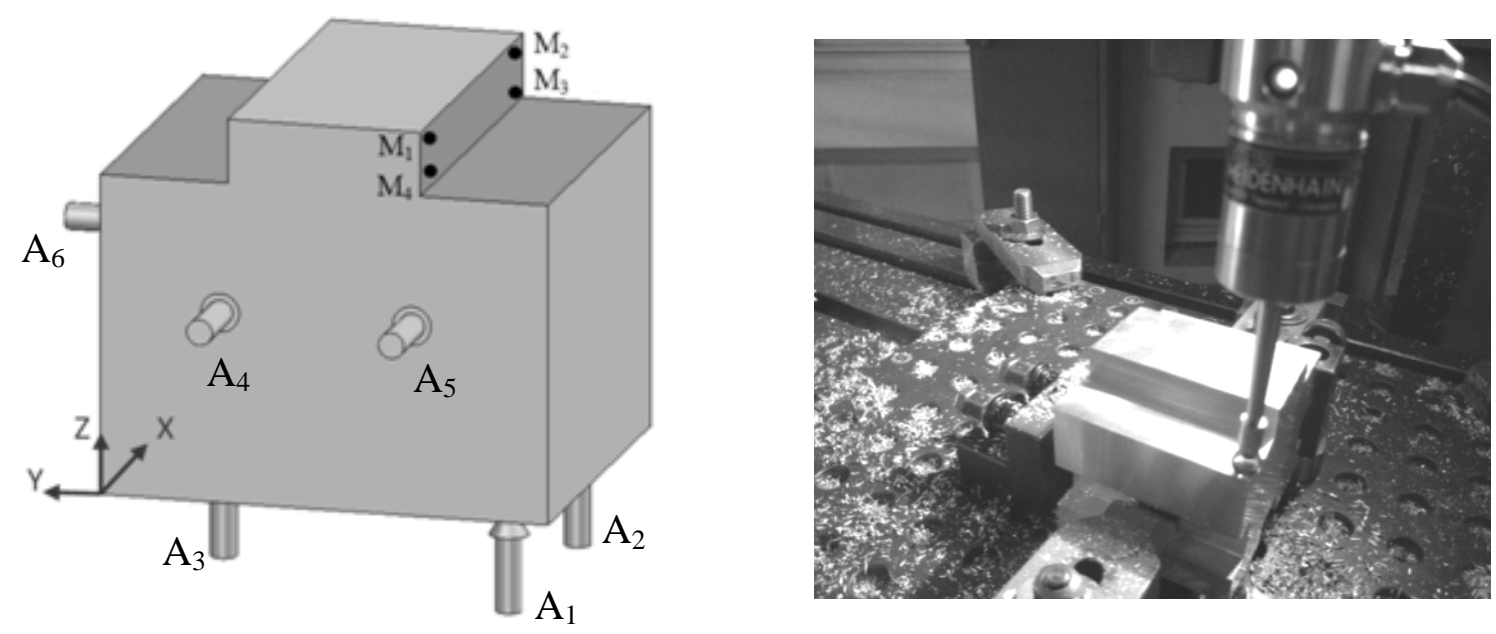

Figure 5: Part-holder in phase 10.

In a machining phase, the defects generated by a manufacturing process are caused by defects in positioning of the workpiece and machining defects. Defects resulting from the positioning of the piece depend on two types of defects:

- Defects of perpendicularity between the three reference surfaces of the part.

- The quality of support, and clamping surfaces.

These random defects were evaluated from measurements made on a series of 50 pieces. Table I gives the characteristic information of the positioning for determining the expression of matrix components $\overline{\bar{\Sigma}}_{p o s, M}$.

Using different dispersions due to work holding errors, and taking into account both the measurement and the coordinates of points of the target surface, we thus obtained the various possible variations in the normal direction normal to the plane of the point $M_{i}$.

Table II contains the information needed to conduct the calculation of the variance of the position at different points in a given direction.

By adding this variance to the variance of machining defects ( $\left.V_{\text {machining }}\right)$ in phase 10 , we obtain the variance of the displacement of points $M_{i}$ of the toleranced surface with respect to the system reference. 
Table I: Dispersion on each part-holder support in phase 10.

\begin{tabular}{|c|c|c|c|c|c|c|}
\hline \multicolumn{7}{|c|}{ Position and orientation of the support (phase 10) } \\
\hline Points & $\boldsymbol{A}_{\mathbf{1}}$ & $\boldsymbol{A}_{\mathbf{2}}$ & $\boldsymbol{A}_{\mathbf{3}}$ & $\boldsymbol{A}_{\mathbf{4}}$ & $\boldsymbol{A}_{\mathbf{5}}$ & $\boldsymbol{A}_{\mathbf{6}}$ \\
\hline $\boldsymbol{X}_{\boldsymbol{A} \boldsymbol{i}}$ & 2,851 & 52,769 & 27,69 & 0 & 0 & 53,321 \\
\hline $\boldsymbol{Y}_{\boldsymbol{A} \boldsymbol{i}}$ & $-59,259$ & $-59,259$ & $-9,463$ & $-21,021$ & $-46,021$ & 0 \\
\hline $\boldsymbol{Z}_{\boldsymbol{A} \boldsymbol{i}}$ & 0 & 0 & 0 & 11,927 & 11,927 & 28,483 \\
\hline $\boldsymbol{n}_{\boldsymbol{x}}$ & 0 & 0 & 0 & -1 & -1 & 0 \\
\hline $\boldsymbol{n}_{\boldsymbol{y}}$ & 0 & 0 & 0 & 0 & 0 & 1 \\
\hline $\boldsymbol{n}_{\boldsymbol{z}}$ & -1 & -1 & -1 & 0 & 0 & 0 \\
\hline Variance $\boldsymbol{\delta}_{\boldsymbol{i}}$ & $\mathbf{2 , 7 4 E - 0 5}$ & $\mathbf{2 , 6 5 E - 0 5}$ & $\mathbf{1 , 7 9 E - 0 5}$ & $\mathbf{6 , 2 9 E - 0 5}$ & $\mathbf{6 , 5 3 E - 0 5}$ & $\mathbf{2 , 0 3 E - 0 4}$ \\
\hline
\end{tabular}

Table II: Dispersions on the target surface in phase 10.

\begin{tabular}{|c|c|c|c|c|}
\hline \multicolumn{5}{|c|}{ Points of the surface1 (Phase 10) } \\
\hline Points & $\boldsymbol{M}_{\mathbf{1}}$ & $\boldsymbol{M}_{\mathbf{2}}$ & $\boldsymbol{M}_{\mathbf{3}}$ & $\boldsymbol{M}_{\mathbf{4}}$ \\
\hline $\boldsymbol{X}$ & 0 & 59 & 59 & 0 \\
\hline $\boldsymbol{Y}$ & 50,5 & $-50,5$ & $-50,5$ & $-50,5$ \\
\hline $\boldsymbol{Z}$ & 59 & 59 & 49 & 49 \\
\hline $\boldsymbol{a}$ & 0 & 0 & 0 & 0 \\
\hline $\boldsymbol{b}$ & -1 & -1 & -1 & -1 \\
\hline $\boldsymbol{C}$ & 0 & 0 & 0 & 0 \\
\hline $\boldsymbol{V}_{\text {positionning }}$ & $1.4939 \mathrm{E}-04$ & $1.7252 \mathrm{E}-04$ & $1.6458 \mathrm{E}-04$ & $1.4145 \mathrm{E}-04$ \\
\hline $\boldsymbol{V}_{\text {machining }}$ & $9,4567 \mathrm{E}-06$ & $1,78 \mathrm{E}-05$ & $1,4649 \mathrm{E}-05$ & $1,4124 \mathrm{E}-05$ \\
\hline total variance & 0,0001588467 & 0,00019032 & 0,000179229 & 0,000155574 \\
\hline $\begin{array}{c}\text { Tolerance } \\
\text { interval (1/0) }\end{array}$ & 0,07562064 & 0,0827739089 & 0,080325861 & 0,074837584 \\
\cline { 2 - 5 } & \multicolumn{5}{|c|}{0,0827739089} \\
\hline
\end{tabular}

\subsection{Influence of dispersions in phase 20}

In phase 20, the studied part is placed on the isostatic part-holder by a primary support $\left(A_{1}, A_{2}\right.$ and $\left.A_{3}\right)$ on the surface 2 , a secondary support $\left(A_{4}\right.$ and $\left.A_{5}\right)$ on the surface $B_{4}$ and tertiary support $\left(A_{6}\right)$ on the surface $B_{3}$.

Fig. 6 illustrates the position of $A_{1}$ to $A_{6}$ and $M_{1}$ to $M_{4}$ in phase 20.
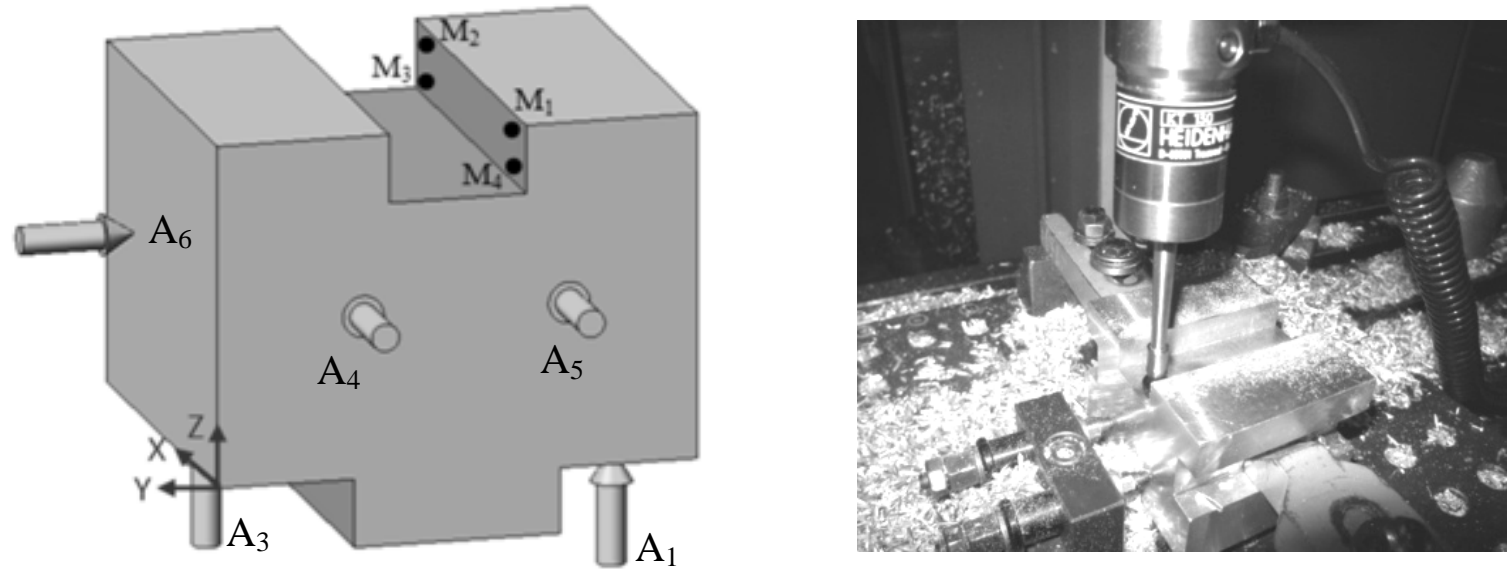

Figure 6: Part-holder in phase 20. 
Table III gives the characteristic information of the positioning for determining the expression of matrix components $\overline{\bar{\Sigma}}_{p o s, M}$ in phase 20 .

Table III: Dispersions on each part-holder support in phase 20.

\begin{tabular}{|c|c|c|c|c|c|c|}
\hline \multicolumn{7}{|c|}{ Position and orientation of the support (phase 20) } \\
\hline Points & $\boldsymbol{A}_{\mathbf{1}}$ & $\boldsymbol{A}_{\boldsymbol{2}}$ & $\boldsymbol{A}_{\mathbf{3}}$ & $\boldsymbol{A}_{\mathbf{4}}$ & $\boldsymbol{A}_{\mathbf{5}}$ & $\boldsymbol{A}_{\mathbf{6}}$ \\
\hline $\boldsymbol{X}_{\boldsymbol{A} \boldsymbol{i}}$ & 3 & 52,77 & 27,7 & 0 & 0 & 53 \\
\hline $\boldsymbol{Y}_{\boldsymbol{A} \boldsymbol{i}}$ & $-59,26$ & $-59,26$ & $-9,46$ & -21 & -46 & 0 \\
\hline $\boldsymbol{Z}_{\boldsymbol{A} \boldsymbol{i}}$ & 0 & 0 & 0 & 12 & 12 & 9,5 \\
\hline $\boldsymbol{n}_{\boldsymbol{x}}$ & 0 & 0 & 0 & -1 & -1 & 0 \\
\hline $\boldsymbol{n}_{\boldsymbol{y}}$ & 0 & 0 & 0 & 0 & 0 & 1 \\
\hline $\boldsymbol{n}_{\boldsymbol{z}}$ & -1 & -1 & -1 & 0 & 0 & 0 \\
\hline Variance $\boldsymbol{\delta}_{\boldsymbol{i}}$ & $\mathbf{1 , 5 1 7 6 E - 0 5}$ & $\mathbf{9 , 8 1 6 E - 0 6}$ & $\mathbf{1 , 2 9 1 E - 0 5}$ & $\mathbf{1 , 2 3 7 4 E - 0 5}$ & $\mathbf{1 , 3 5 E - 0 5}$ & $\mathbf{1 , 6 3 2 7 E - 0 5}$ \\
\hline
\end{tabular}

To obtain the variance, the same procedure used in phase 10 is applied. Table IV present the displacement variance of the toleranced surface (6) summits points $\left(M_{i}\right)$ in its normal direction with respect to the reference system of the manufacturing specification in phase 20.

Table IV: Dispersions on the target surface (6) in phase 20.

\begin{tabular}{|c|c|c|c|c|}
\hline \multicolumn{5}{|c|}{ Points of the surface 6 (Phase 20) } \\
\hline Points & $\boldsymbol{M}_{\mathbf{1}}$ & $\boldsymbol{M}_{\mathbf{2}}$ & $\boldsymbol{M}_{\mathbf{3}}$ & $\boldsymbol{M}_{\mathbf{4}}$ \\
\hline $\boldsymbol{X}$ & 0 & 59 & 59 & 0 \\
\hline $\boldsymbol{Y}$ & -45 & -45 & -45 & -45 \\
\hline $\boldsymbol{Z}$ & 49 & 49 & 39 & 39 \\
\hline $\boldsymbol{b}$ & 0 & 0 & 0 & 0 \\
\hline $\boldsymbol{C}$ & -1 & -1 & -1 & -1 \\
\hline $\boldsymbol{V}_{\text {positionning }}$ & $1.4145 \mathrm{E}-04$ & $1.6458 \mathrm{E}-04$ & $1.5811 \mathrm{E}-04$ & $1.3498 \mathrm{E}-04$ \\
\hline $\boldsymbol{V}_{\text {machining }}$ & $1,46465 \mathrm{E}-05$ & $1,4816 \mathrm{E}-05$ & $1,5098 \mathrm{E}-05$ & $1,47 \mathrm{E}-05$ \\
\hline total variance & 0,0001560965 & 0,000179396 & 0,000173208 & 0,00014968 \\
\hline $\begin{array}{c}\text { Tolerance } \\
\text { interval (6/0) }\end{array}$ & 0,07496315 & 0,07936327 & 0,07896510 & 0,07340626 \\
\cline { 2 - 5 } & \multicolumn{5}{|c|}{0,07936327} \\
\hline
\end{tabular}

\subsection{Results and comparisons}

Considering a normal distribution following the distributions shown in Figs. 8, 9 and 10, the dispersion is evaluated in its maximum result as follows:

- Phase 10: 0.0827 for a variance 0.00019

- Phase 20: 0.0793 for a variance 0.000179

- Localisation (C3): 0.281 for a variance 0.0067081.

To check the consistency of simulation results with respect to experimental results, a comparison is made with measurements on a series of 50 pieces shown in Fig. 7. The results of the computed accumulation of the manufacturing defects generated by two phases (partholder defects, workpiece locating dispersion and machining defects) is then compared with the values determined after final control of the functional condition C3 over the coordinate 
measuring machine (CMM). Table V shows this comparison. It is observed that the difference between the analytical model and experimental measurement is reasonably small.
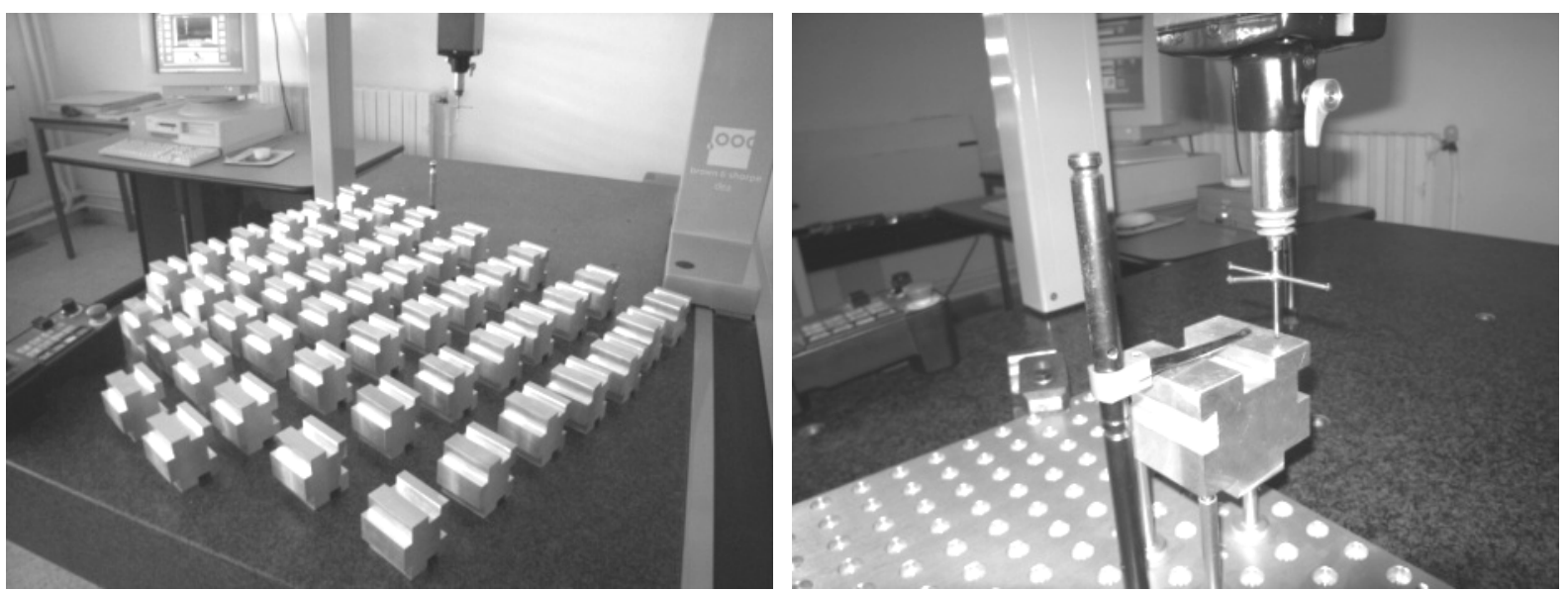

Figure 7: Final inspection on CMM.

Figs. 8, 9 and 10 display the normal probability plots of the sample data and from these figures the sample data seems to be normal. The histograms of the 50 observations with a density line and specification limit (LSL, T, USL) and the results of the process-capability analysis are displayed.
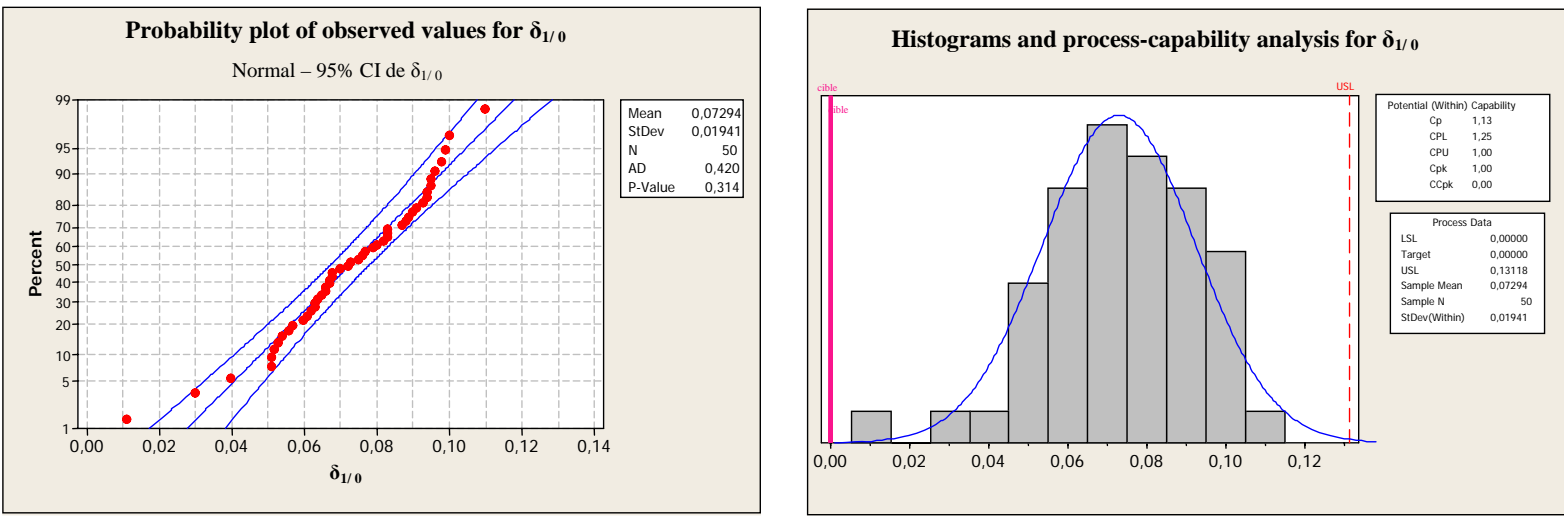

Figure 8: Distribution of measured values (phase 10).
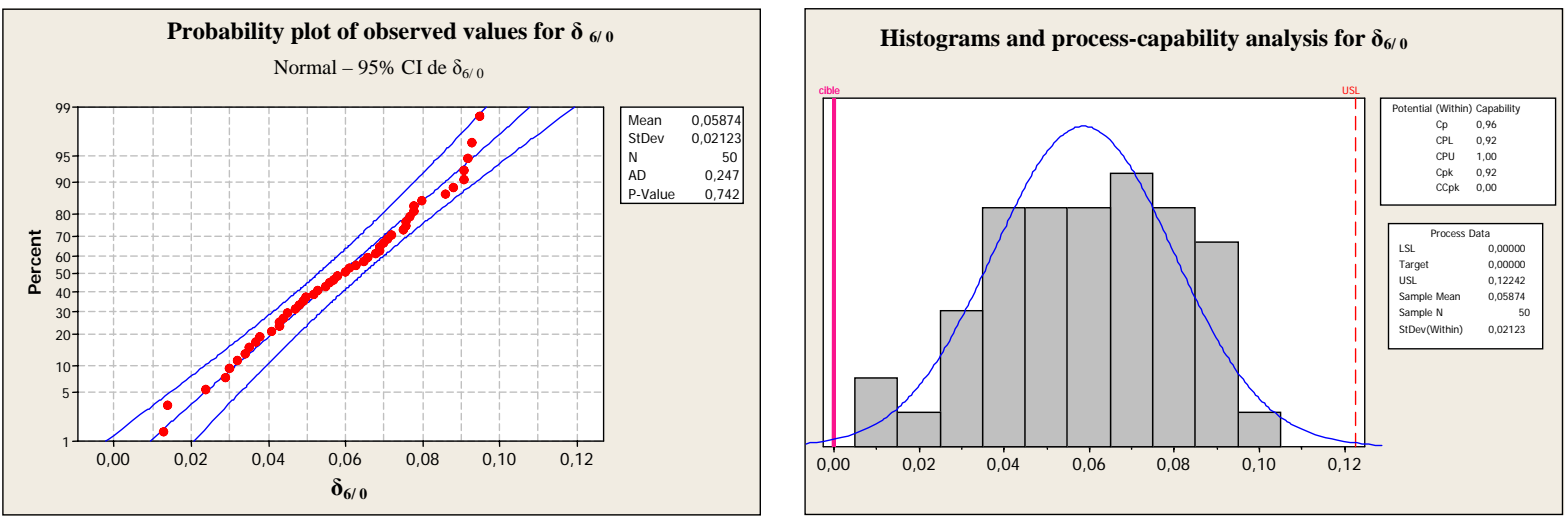

Figure 9: Distribution of measured values (phase 20). 

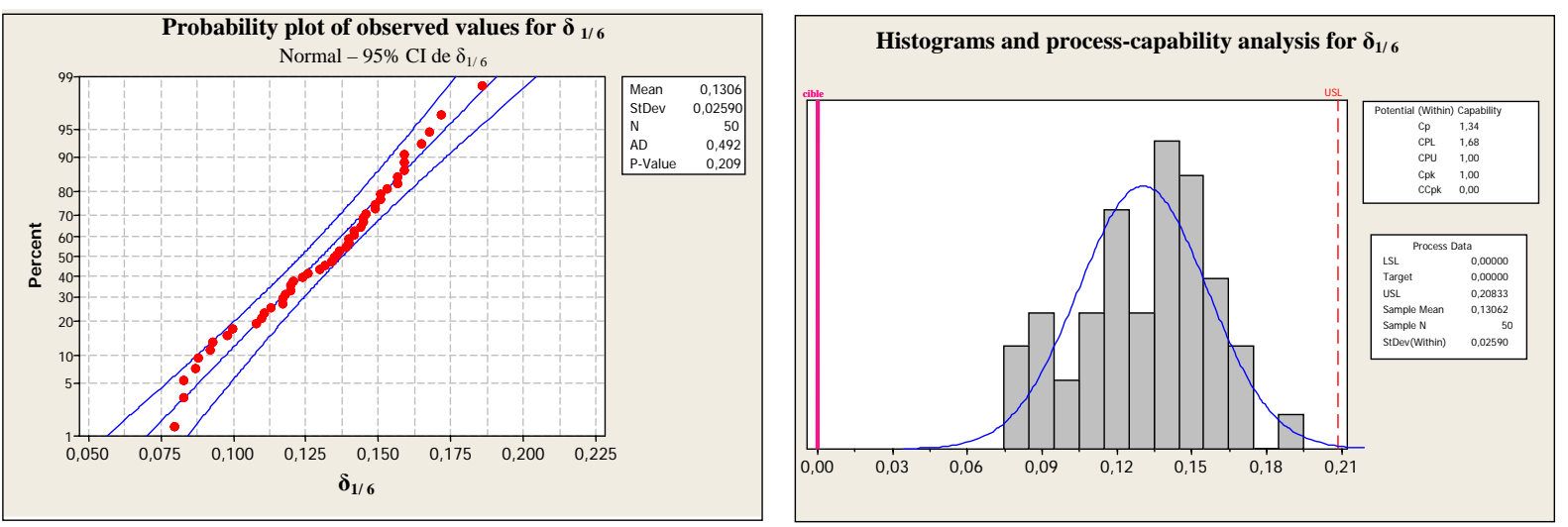

Figure 10: Distribution of measured values $\delta_{1 / 6}(C 3)$.

Table V: Comparison between simulation and experimental results.

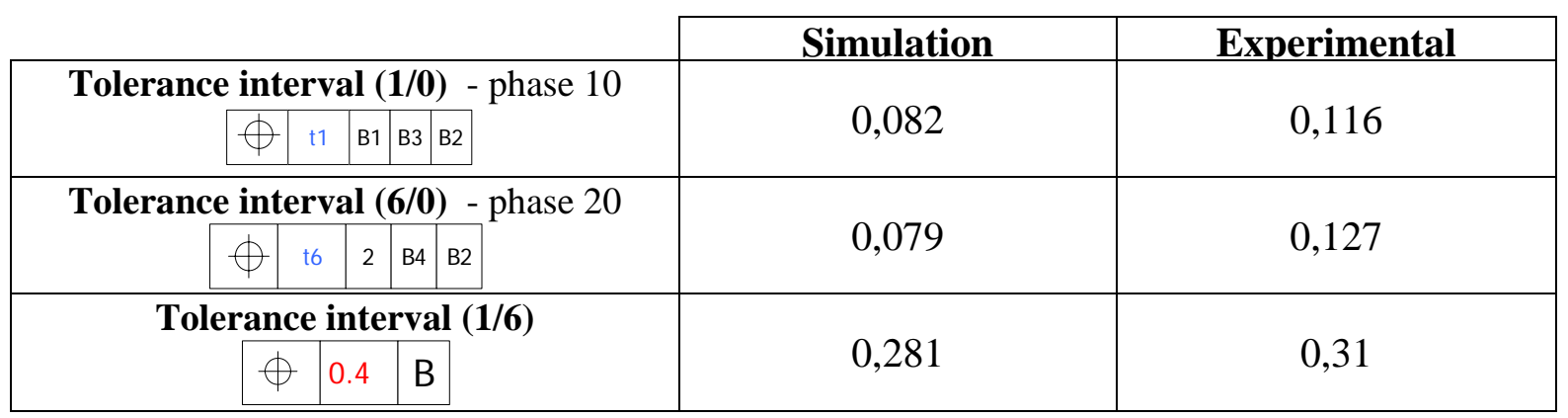

\section{CONCLUSION}

A three-dimensional statistical approach for determining the manufacturing tolerances has been presented, based on the components of the small displacements torsors which are considered as random variables. Passing from a part to a series of manufactured parts is obtained not by considering small displacements (representative of geometric defects) but by the variance on these displacements. Through a three-dimensional simulation method, we determine the geometric tolerance values of different manufacturing specifications. The input data for simulation are estimated variance and the results be expressed, too, for a variance. An experimental campaign was set up which consists of measuring various defects on machinetool and then ensuring that the defects obtained on the final part are in good agreement with those obtained from simulation. It was found out that the difference was reasonably small. Following these studies an automatic tool based on software can be developed to respond to the increasing needs of industrials in this field.

\section{REFERENCES}

[1] Rui, W.; Thimm, G. L.; Yongsheng, M. (2010). Review: geometric and dimensional tolerance modelling for sheet metal forming and integration with CAPP, International Journal of Advanced Manufacturing Technology, Vol. 51, No. 9-12, 871-890, doi:10.1007/s00170-010-2663

[2] Anselmetti, B.; Bourdet, P. (1993). Optimisation of a workpiece considering production requirements, Computers in Industry, Vol. 21, 23-34, doi:10.1016/0166-3615(93)90042-Y

[3] Duret, D. (1995). Détermination des intervalles de tolérance en fabrication par une approche graphique, Actes séminaire tolérancement et chaînes de cotes, ENS Cachan

[4] Bouaziz, Z.; Masmoudi, F. (2006). Manufacturing simulation: Computer aided tolerancing for process planning, International Journal of Simulation Modelling, Vol. 5, No. 1, 5-15, doi:10.2507/IJSIMM05(1)1.059 
Barkallah, Louati, Haddar: Evaluation of Manufacturing Tolerance Using a Statistical ...

[5] Portman, V. T. (1995). Modelling spatial dimensional chains for CAD/CAM applications, Proceedings of the $4^{\text {th }}$ CIRP Design Seminar on Computer-Aided Tolerancing, Vol. 5, No. 6, 7185

[6] Laperriere, L.; ElMaraghy, H. (2000). Tolerance analysis and synthesis using Jacobian transforms. Annals of the CIRP, Vol. 49, No. 1, 359-362, doi:10.1016/S0007-8506(07)62964-3

[7] Bourdet, P.; Mathieu, L.; Lartigue, C.; Ballu, A. (1996). The concept of the small displacement torsor in metrology, Advanced Mathematical and Computational Tools in Metrology (AMCTM), Vol. 40, 110-122

[8] Desrochers, A.; Riviere, A. (1997). A matrix approach to the representation of tolerance zones and clearances, The International Journal of Advanced Manufacturing Technology, Vol. 13, 630636, doi:10.1007/BF01350821

[9] Villeneuve, F.; Lego, O.; Landon, Y. (2001) Tolerancing for manufacturing: a three-dimensional model, International Journal of Production Research, Vol. 39, No. 8, 1625-1648, doi:10.1080/00207540010024104

[10] Brajlih, T.; Tasic, T.; Drstvensek, I.; Valentan, B.; Hadzistevic, M.; Pogacar, V.; Balic, J.; Acko, B. (2011). Possibilities of Using Three-Dimensional Optical Scanning in Complex Geometrical Inspection, Strojniski vestnik - Journal of Mechanical Engineering, Vol. 57, No. 11, 826-833, doi:10.5545/sv-jme.2010.152

[11] Villeneuve, F.; Vignat, F. (2003). 3D synthesis of manufacturing tolerances using a SDT approach, The $8^{\text {th }}$ CIRP International Seminar on Computer Aided Tolerancing, Charlotte, North Carolina, Vol. 41, No. 3, 279-290

[12] Chaari, R.; Abdennadher, M.; Louati, J.; Haddar, M. (2011). Modelling of the 3D Machining Geometric Defects Accounting for Workpiece Vibratory Behaviour, International Journal of Simulation Modelling, Vol. 10, No. 2, 66-77, doi:10.2507/IJSIMM10(2)2.173

[13] Varghese, P.; Zhang, C.; Wang, H. (1996). Geometric tolerance analysis with vectorial tolerancing, Engineering Design \& Automation, Vol. 31, No. 2, 127-139

[14] Huang, S. H.; Liu, Q.; Musa, R. (2004). Tolerance-based Process Plan Evaluation using Monte Carlo Simulation, International Journal of Production Research, Vol. 42, 4871-4891, doi:10.1080/0020754042000264608

[15] Anselmetti, B.; Louati, H. (2005). Generation of manufacturing tolerancing with ISO standards, International Journal of Machine Tools and Manufacture, Vol. 45, No. 10, 1124-1134, doi:10.1016/j.ijmachtools.2005.01.001

[16] Clément, A.; Rivière, A.; Temmerman, M. (1994). Cotation tridimensionnelle des systèmes mécaniques, PYC Edition

[17] Jaballi, K.; Bellacicco, A.; Louati, J.; Rivière, A.; Haddar, M. (2009). Dimensioning of the intermediate states of the machined phases "DISMP approach", International Journal of Advanced Manufacturing Technology, Vol. 45, No. 9, 907-921, doi:10.1007/s00170-009-2040-9

[18] Jaballi, K.; Bellacicco, A.; Louati, J.; Rivière, A.; Haddar, M. (2011). Rational method for 3D manufacturing tolerancing synthesis based on the TTRS approach "R3DMTSyn", Computers in Industry, Vol. 62, No. 5, 541-554, doi:10.1016/j.compind.2011.02.003

[19] Hu, J.; Xiong, G. (2005). Concurrent design of geometric parameter and tolerance for assembly and cost, International Journal of Production Research, Vol. 43, No. 2, 267-294, doi:10.1080/00207540412331282051

[20] Flores, P. (2011). A Methodology for Quantifying the Kinematic Position Errors due to Manufacturing and Assembly Tolerances, Strojniski vestnik - Journal of Mechanical Engineering, Vol. 57, No. 6, 457-467, doi:10.5545/sv-jme.2009.159

[21] Hu, J.; Peng, Y. (2007). Tolerance modelling and robust design for concurrent engineering, Journal of Mechanical Engineering Science, Vol. 221, 455-465, doi:10.1243/0954406JMES438

[22] Zhao, X.; Kethara Pasupathy, T. M.; Wilhelm, R. G. (2006). Modeling and representation of geometric tolerances information in integrated measurement processes, Computers in Industry, Vol. 57, No. 4, 319-330, doi:10.1016/j.compind.2005.09.004

[23] Gaunet, G. (1991). Modèle formel de Tolérancement de position. Contributions à l'aide au Tolérancement des mécanismes en CFAO, Thèse de l'école normale supérieure de Cachan 